\title{
Analisis Luas dan Volume Sedimen pada Kanal Intake untuk Menjaga Ketersediaan Pasokan Air (Studi Kasus : PLTGU Muara Tawar, Bekasi Utara)
}

\author{
Juli Arianto, N. M. R. Ratih C. Perbani, M. F. P. Kusumah \\ Jurusan Teknik Geodesi, FTSP - Insitut Teknologi Nasional, Bandung \\ Email: juliarianto07@gmail.com
}

\begin{abstract}
ABSTRAK
PLTGU Muara Tawar merupakan salah satu pembangkit listrik yang menggunakan air laut untuk proses pendinginannya. Air laut tersebut disalurkan melalui kanal intake di mana sedimen yang berada di kanal intake akan mempengaruhi pasokan air. Untuk itu dalam menjaga ketersediaan pasokan air pada kanal intake perlu diketahui luas dan volume sedimennya. Penelitian ini bertujuan untuk mengetahui drying height pada saat air terendah, pola penyebaran sedimen, perubahan luas sedimen, kondisi kedalaman kritis, dan perubahan volume air dan sedimen antara Maret 2013 dan Desember 2014. Data yang digunakan berupa data posisi permukaan sedimen dan pasut pada Bulan Maret-April 2013 dan Desember 2014. Pada tahun 2013 didapatkan informasi bahwa pasokan air yang tersedia hanya 32,75\% sementara di tahun 2014 hanya $32,69 \%$ dari syarat aman. Dengan demikian untuk memenuhi syarat aman pasokan air maka sedimen sampai 6 meter di bawah MSL yang harus dikeruk baik di tahun 2013 maupun 2014 sebesar lebih dari $60 \%$.
\end{abstract}

Kata kunci: kanal intake, sedimen, pasokan air

\begin{abstract}
PLTGU Muara Tawar is one of the power plants that use sea water as a coolant. The sea water is channeled through the intake canal where sediments in it will affect the water supply. For maintaining the water supply in intake canal it is necesssary to have an information about sediment area and volume. This study schemes are to determine the drying height at lowest low water, sediment distribution, changes in sediment area, critical depth condition, and changes in the volume and sediment beetween March 2013 and December 2014. The data used are the position of the sediment surface and the tide height on March to April 2013 and Desember 2014. It is obtained that for safety requirements the water supply left only 32,75\% in 2013 and reduced to 32,69\% in 2014. So, to achieve the safety requirements of water supply in 2013 and 2014 the sediment ought to be dredged more than 60\% from 6 meter below MSL base.
\end{abstract}

Keywords: intake canal, sediment, water supply 


\section{PENDAHULUAN}

Unit Pembangkitan (UP) Muara Tawar adalah sebuah Unit Pembangkitan Listrik Tenaga Gas Uap (PLTGU) yang dikelola oleh PT Pembangkitan Jawa-Bali (PJB) yang terletak di Kabupaten Bekasi, Jawa Barat. Sesuai dengan konsep pembangkitannya yang menggunakan gas uap, air laut yang digunakan untuk proses pendinginan masuk melalui kanal intake sepanjang 2,790 km lalu masuk ke dalam area kolam penenang sepanjang 128,8 meter untuk kemudian disalurkan melalui water intake untuk menggerakkan turbin pada generator UP Muara Tawar.

Berdasarkan laporan [1] water intake merupakan salah satu bagian penting pada rangkaian proses pembangkitan listrik. Water intake merupakan sistem pendingin PLTGU yang menggunakan air laut sebagai pendingin utama. Seiring dengan bertambahnya waktu maka memungkinkan sedimen yang dibawa arus laut akan mengendap dan semakin bertambah banyak. Dengan bertambahnya sedimen yang masuk ke dalam kanal intake maka pasokan air yang masuk ke dalam water intake akan berkurang.

Dalam [2] [dinyatakan bahwa perilaku air laut yang dipengaruhi oleh pasang surut akan berpengaruh pada kwalitas air yang masuk dan juga kwantitasnya. Hal ini dapat dipahami karena ketika air laut masuk ke dalam area kanal intake, air tersebut mendorong material sedimen yang berada di bawahnya. Ketika air pasang, material tersebut terbawa ke dalam area kanal, sedangkan ketika surut hanya separuh material endapan saja yang mungkin terbawa kembali ke laut lepas. Oleh karena itu endapan/sedimen yang berada di area kanal intake dan kolam penenang yang berasal dari air laut tersebut akan sangat mempengaruhi volume pasokan air yang nantinya digunakan sebagai pendingin. Semakin tinggi volume sedimen yang berada di area kanal intake maka semakin berkurang pula volume air yang dapat dimanfaatkan untuk menunjang kegiatan produksi energi listrik. Untuk mengatasi hal tersebut menurut [3] perlu dilakukan pengerukan pada kanal intake untuk mendapatkan suatu kedalaman tertentu. Sebelum pelaksanaan pengerukan tersebut harus diketahui berapa luas daerah dan bentuk dasar yang akan dikeruk dan berapa volumenya sehingga pekerjaan ini dapat dilakukan seefektif mungkin. Pada penelitian ini akan dicoba untuk mengetahui luas daerah dan volume di kedalaman tertentu untuk menjamin tersedianya pasokan air di kanal intake PLTGU Muara Tawar.

PLTGU Muara Tawar merupakan salah satu pembangkit listrik yang menggunakan air laut untuk proses pendinginannya. Air laut tersebut disalurkan melalui kanal intake di mana sedimen yang berada di kanal intake akan mempengaruhi pasokan air. Untuk itu dalam menjaga ketersediaan pasokan air pada kanal intake perlu diketahui luas dan volume sedimen sehingga masalah-masalah dalam penelitian ini dapat dirumuskan seperti berikut ini: apakah terjadi drying height pada saat kejadian air paling rendah; bagaimana pola penyebaran sedimen pada kanal intake; seberapa besar perubahan luas sedimen pada profil melintang di kanal intake; seberapa banyak profil melintang yang mengalami kondisi kritis pada kanal intake; dan berapa perubahan volume air dan sedimen yang terjadi pada kanal intake antara Maret 2013 dan Desember 2014.

Penelitian ini bertujuan untuk mengetahui drying height pada saat air terendah, pola penyebaran sedimen, perubahan luas sedimen, kondisi kedalaman kritis, dan perubahan volume air dan sedimen antara Maret 2013 dan Desember 2014. Manfaat dalam penelitian ini adalah untuk mengetahui perkiraan luas dan volume sedimen pada kanal intake yang selanjutnya akan dilakukan pengerukan sebagai tindakan pencegahan agar pasokan air yang digunakan untuk produksi energi listrik tetap terjaga. Dengan diketahuinya volume air dan sedimen serta kedudukan air yang paling terendah maka syarat-syarat tertentu dalam menjaga pasokan air pada mesin generator dapat diketahui.

Batasan masalah yang ditetapkan pada tugas akhir ini adalah: kejadian air paling rendah diambil dari data pengamatan pasut; syarat kedalaman kritis ditentukan berdasarkan syarat yang ditetapkan untuk PLTGU Muara Tawar, yaitu 3 meter terhadap Mean Sea Level (MSL); syarat kedalaman aman ditentukan berdasarkan syarat yang ditetapkan untuk PLTGU Muara Tawar, yaitu $6 \mathrm{~m}$ terhadap Mean 
Sea Level (MSL); hitungan luas dan volume sedimen menggunakan Aturan Pertama Simpson; hitungan luas dan volume air bukan direferensikan pada muka air sesaat, tapi terhadap MSL.

\section{METODOLOGI}

Daerah studi pada penelitian ini berlokasi di dalam area kerja Pembangkit Listrik Tenaga Gas Uap (PLTGU) Muara Tawar, Desa Segara Jaya, Kecamatan Taruma Jaya, Kabupaten Bekasi - Provinsi Jawa Barat. Secara geografik wilayah penelitian terletak di sekitar $106^{\circ} 59^{\prime} 56.27^{\prime \prime}$ Bujur Timur dan $6^{\circ}$ 5' 13.73" Lintang Selatan. Ilustrasi PLTGU wilayah studi yang diperoleh dari Google Earth dapat dilihat pada Gambar 1.

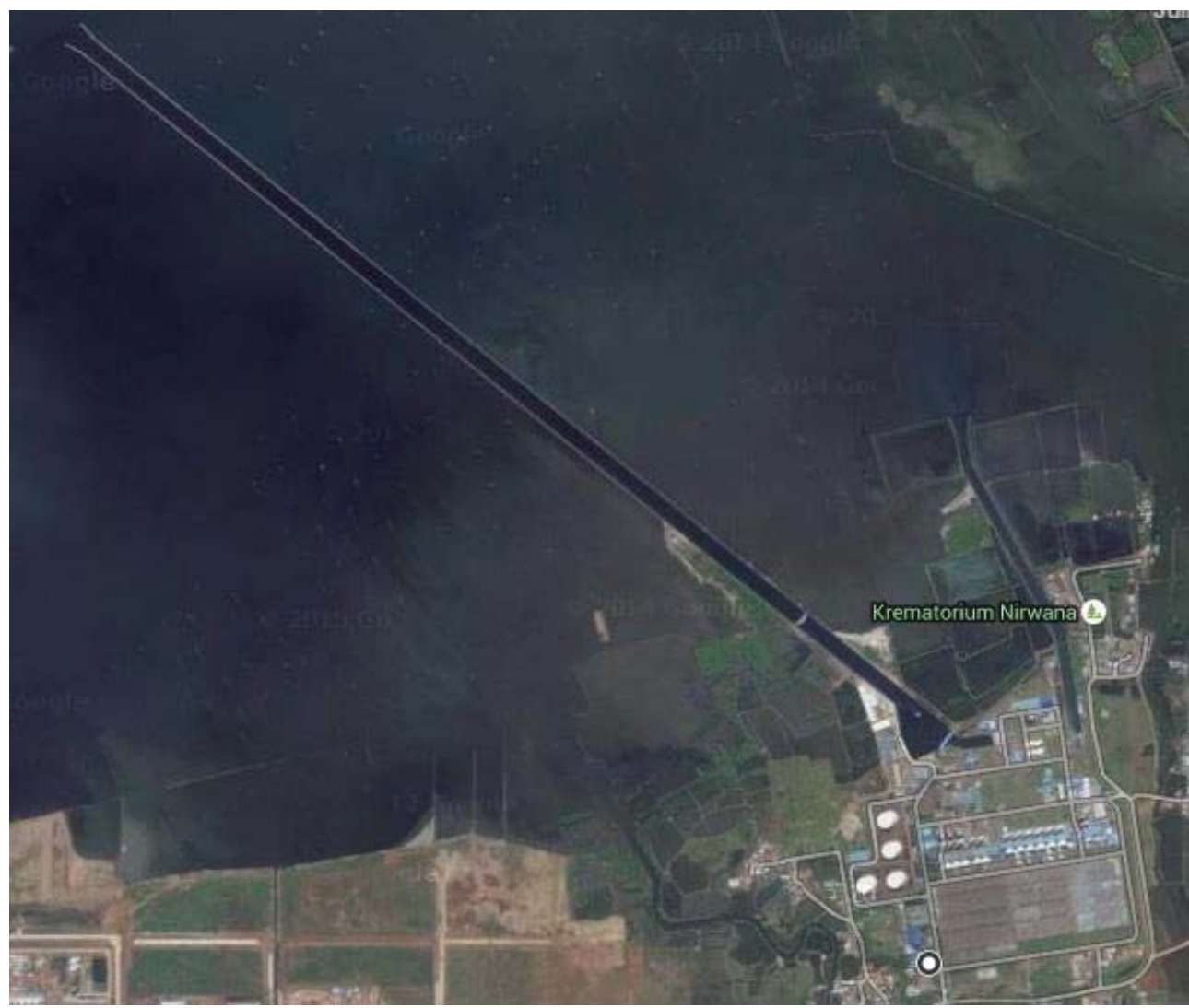

Gambar 1 Cakupan Wilayah Penelitian (Sumber: Google Earth, 2013)

Metodologi yang digunakan dalam penentuan luas dan volume sedimen pada kanal intake untuk ketersediaan pasokan air dapat dilihat pada Gambar 2. 


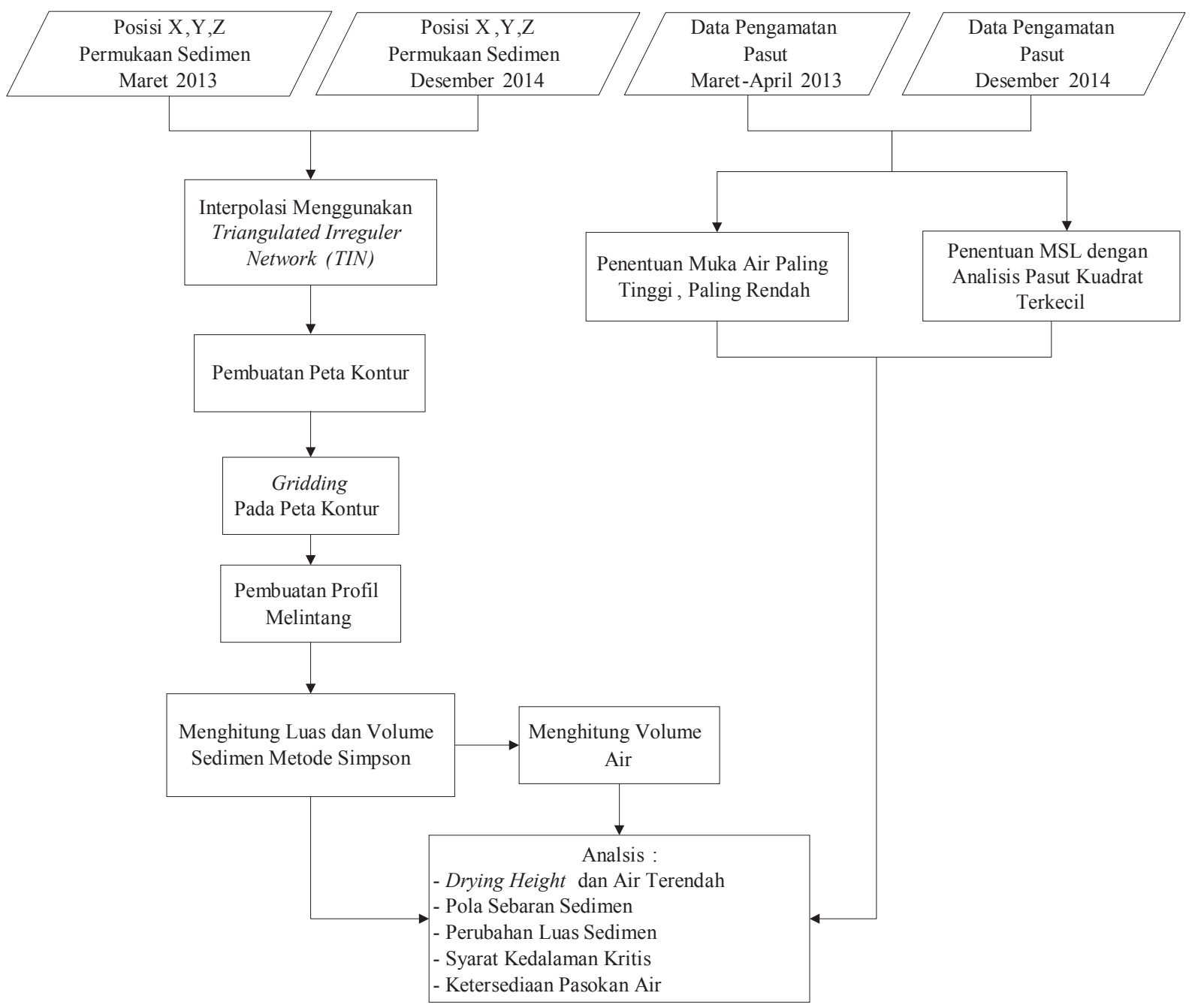

Gambar 2 Metodologi Penelitian

Tahapan pembuatan grid berdasarkan polyline secara manual dengan jarak (offset) per interval grid mengikuti kriteria dari peta kontur, yaitu rencana jarak antar grid disesuaikan dengan kondisi bentuk kontur dengan memperhatikan daerah-daerah ekstrem seperti penumpukan sedimen sehingga pola sebaran sedimen dapat terlihat lebih jelas. Proses gridding ini bertujuan untuk membantu penggambaran profil melintang agar penumpukan sedimen dan yang sama rata/datar dengan pola sebarannya dapat terlihat lebih jelas pada suatu grafik dan agar lebih mudah diidentifikasi sehingga hitungan volumenya menjadi lebih detail. Pada rencana pembuatan grid setiap garis grid diberi keterangan (label) yang dinamakan seperti IT-01 yaitu IT (Kanal Intake)-01 agar posisi label grid untuk profil melintang lebih mudah diketahui. Interval antar profil diusahakan sedetail mungkin dengan memperhatikan daerah-daerah ekstrem. Pada penelitian ini grid yang telah dibuat ada 279 grid dengan selang 10 meter dengan sampel yang ditunjukkan pada Gambar 3. 


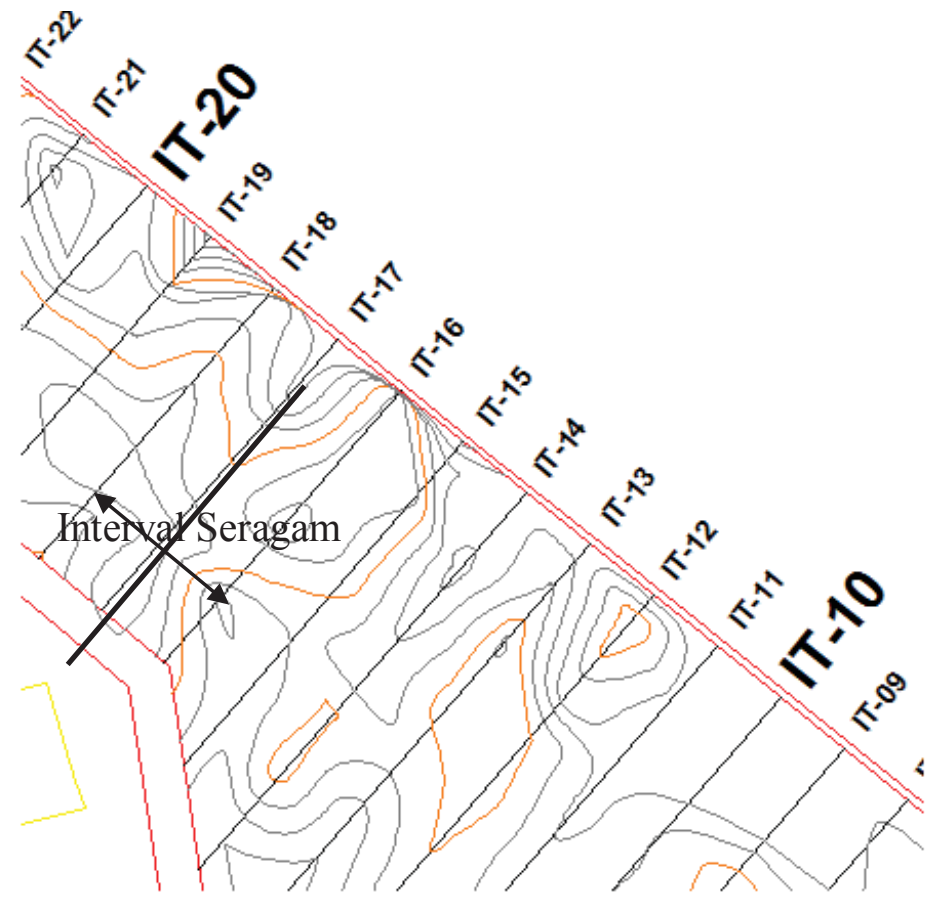

Gambar 3 Sampel Profil Melintang IT-16

Selanjutnya dilakukan penentuan nilai ordinat berdasarkan profil yang telah dibuat. Sebagai contoh hitungan digunakan Profil Melintang IT-16 pada Bulan Maret 2013 seperti Gambar 4.

Profil Melintang IT-16

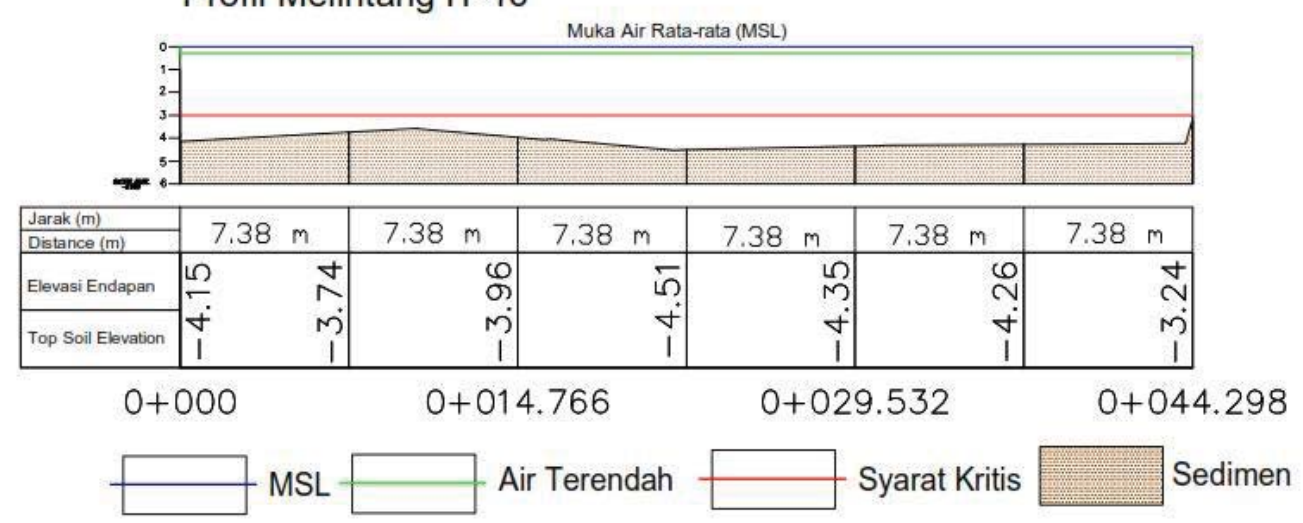

Gambar 4 Profil Sedimen Dengan Dasar 6 Meter di Bawah MSL

Syarat aman untuk kedalaman water intake yang ditetapkan oleh UP Muara Tawar adalah $6 \mathrm{~m}$ di bawah MSL sehingga pada penelitian ini sedimen yang dihitung mulai dari dasar sedimen 6 meter di bawah MSL dan syarat kondisi kritis 3 meter di bawah MSL. Interval pada setiap profil melintang dibagi ke dalam tujuh ordinat dengan antar absis memiliki jarak sama seperti yang dapat dilihat pada Gambar 5.

Profil Melintang IT-16

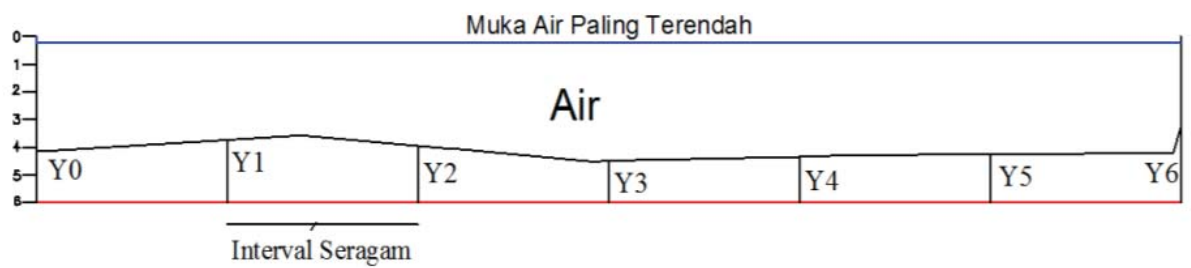

Gambar 5 Sistem Absis dan Ordinat pada Profil Melintang IT-16

Jurnal Rekayasa Hijau - 84 
Pada Aturan Pertama Simpson untuk menghitung luas jumlah ordinat yang dibutuhkan berjumlah ganjil sehingga jumlah ruang partisi yang dibentuk berjumlah genap. Dapat dilihat pada Gambar 5 bahwa jumlah ordinat pada sistem absis dan ordinat diatur berjumlah ganjil dengan interval seragam maka untuk menghitung luas dapat digunakan Aturan Pertama Simpson. Dalam bentuk tabel penerapan aturan tersebut untuk profil melintang pada Bulan Maret 2013 dapat dilihat pada Tabel 1.

Tabel 1 Hitungan Luas Profil Melintang di IT-16 (Maret 2013)

\begin{tabular}{|c|c|c|c|}
\hline No. Titik & $\begin{array}{c}\text { H } \\
(\mathbf{m})\end{array}$ & SM & $\begin{array}{c}\text { L = H.SM } \\
(\mathbf{m})\end{array}$ \\
\hline 0 & 1,851 & 1 & 1,851 \\
\hline $\mathrm{y} 1$ & 2,263 & 4 & 9,052 \\
\hline $\mathrm{y} 2$ & 2,037 & 2 & 4,074 \\
\hline $\mathrm{y} 3$ & 1,493 & 4 & 5,972 \\
\hline $\mathrm{y} 4$ & 1,653 & 2 & 3,306 \\
\hline $\mathrm{y} 5$ & 1,735 & 4 & 6,940 \\
\hline $\mathrm{y} 6$ & 2,759 & 1 & 2,759 \\
\hline
\end{tabular}

$$
\begin{array}{llr}
\text { Interval antar ordinat } & \mathrm{h}= & 7,380 \mathrm{~m} \\
\text { Luas Penampang } & \mathrm{L}_{\mathrm{P}}=2 \cdot \frac{1}{3} \cdot \mathrm{h} \cdot \sum \mathrm{L}= & 167,05368 \mathrm{~m}^{2}
\end{array}
$$

Keterangan: H adalah ordinat-ordinat pada profil melintang dan SM merupakan koefisien Aturan Pertama Simpson yang merupakan pengali untuk masing-masing ordinat.

Untuk menghitung volume sedimen digunakan Aturan Pertama Simpson untuk volume. Dalam bentuk tabel penerapan aturan tersebut untuk profil melintang dicontohkan pada lokasi Grid IT-01 sampai dengan IT-23 dapat dilihat pada Tabel 2.

Tabel 2 Sebagian Hitungan Volume Sedimen dari IT-01 sampai dengan IT-23 (2013)

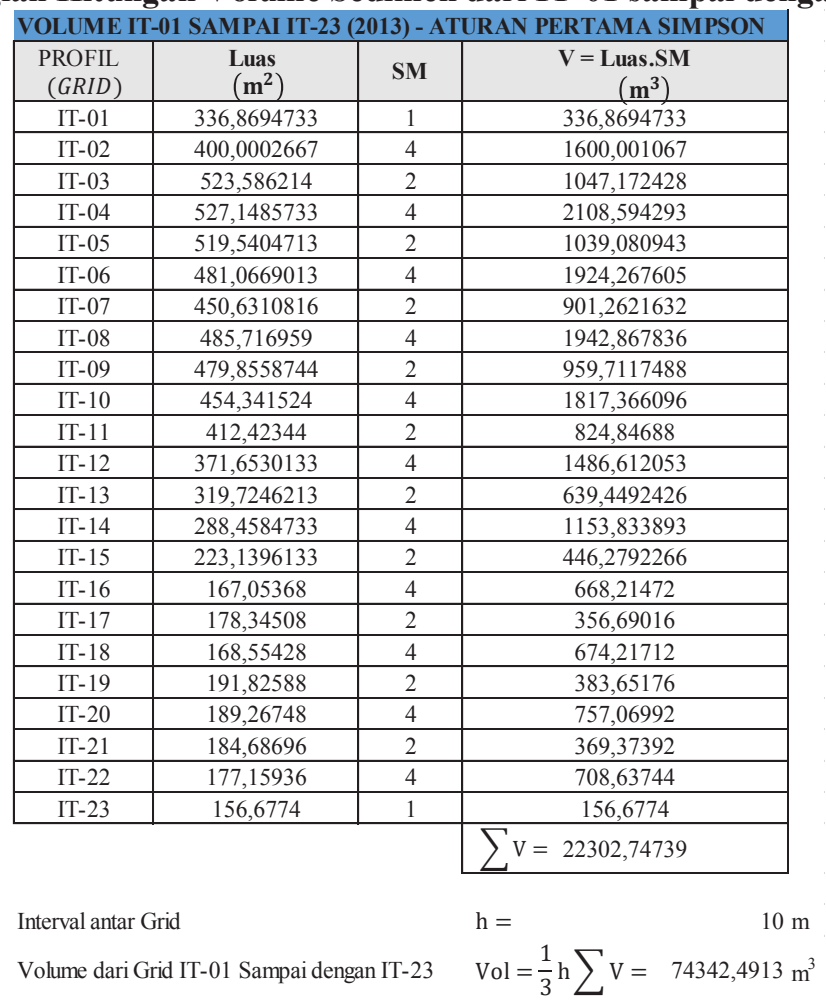

Keterangan: SM merupakan koefisien Aturan Pertama Simpson yang merupakan pengali untuk masingmasing luas Profil Melintang 


\subsection{Air terendah}

\section{HASIL DAN PEMBAHASAN}

Kedudukan muka air yang terjadi pada kanal intake PLTGU Muara Tawar pada Bulan Maret 2013 dan Desember 2014, dapat dilihat pada Tabel 3.

Tabel 3 Kedudukan Muka Air Terhadap Rambu Pasut di Kanal Intake PLTGU Muara Tawar

\begin{tabular}{l|c|c}
\multicolumn{1}{c|}{ Permukaan Air } & $\begin{array}{c}\text { Maret 2013 } \\
(\mathbf{~ m ~})\end{array}$ & $\begin{array}{c}\text { Desember14 } \\
(\mathbf{~ m ~})\end{array}$ \\
\hline Mean Sea Level (MSL) & 0,74 & 0,60 \\
\hline Kedudukan air paling rendah & 0,44 & 0,22 \\
\hline Kedudukan air paling tinggi & 1,05 & 1,16 \\
\hline Tunggang air & 0,61 & 0,94 \\
\hline
\end{tabular}

Kedudukan air terendah terhadap MSL pada tahun 2013 adalah $-0,30$ meter sedangkan pada tahun 2014 adalah $-0,38$ meter. Dari Tabel 3 dapat dilihat bahwa perbedaan air paling tinggi dengan paling rendah (tunggang air) pada tahun 2013 sebesar 0,61 meter dan tahun 2014 sebesar 0,94 meter. Tunggang air yang terjadi di tahun 2013 dan 2014 kurang dari satu meter sehingga dapat dikatakan bahwa naik turunnya muka air yang disebabkan oleh pasut tidak terlalu ekstrem. Hal ini juga didukung data kedudukan muka air paling rendah di bawah MSL di tahun 2013 sebesar -0,30 meter dan di tahun 2014 sebesar $-0,38$ meter.

Permukaan sedimen pada tahun 2013 berkisar dari -4,74 meter sampai dengan -1,01 meter, sedangkan di tahun 2014 berkisar dari -5,60 meter sampai -1,21 meter. Dengan demikian sedimen paling tebal pada kanal intake pada umumnya berada lebih dari satu meter di bawah MSL sehingga pada saat terjadi kedudukan muka air paling rendah tidak terjadi drying height. Menurut [4] drying height adalah tinggi di atas chart datum yang merupakan dasar laut yang tidak terlihat dan terekspos secara periodik oleh pasang surut.

Untuk mendeteksi fenomena drying height seharusnya menggunakan permukaan air terendah berupa LAT. Untuk memprediksi LAT menurut [5] diperlukan data pasut minimal satu tahun. Pada penelitian ini data yang tersedia tidak cukup untuk memprediksi LAT sehingga kedudukan air paling terendah tidak diprediksi, tetapi dilihat langsung dari data pasut yang tersedia. Walaupun LAT tidak dapat diprediksi, akan tetapi drying height masih belum terjadi meskipun pendangkalan sudah mulai terjadi kurang dari satu meter, yaitu sebesar 0,71 meter pada tahun 2013 dan 0,83 meter pada tahun 2014.

\subsection{Pola Sebaran Sedimen}

Pada penelitian ini pola sebaran sedimen dilihat berdasarkan hasil peta kontur yang berbentuk tiga dimensi pada Bulan Maret 2013 dan Desember 2014 yang dapat di lihat pada Gambar 6.
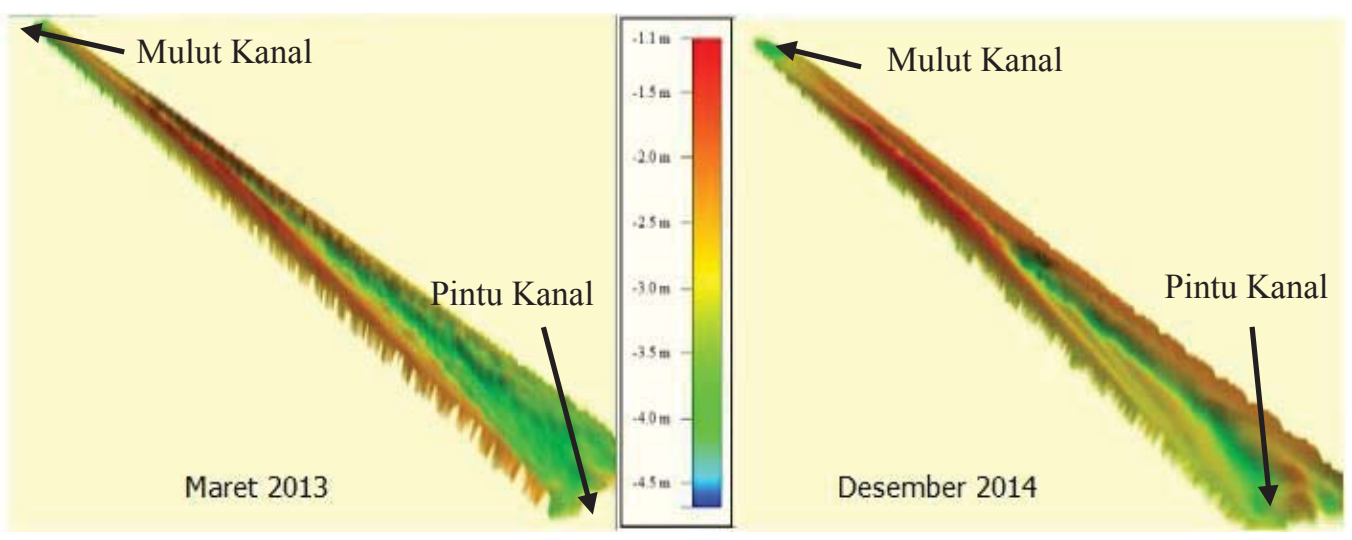

Gambar 6. Pola Sebaran Sedimen Mulai dari Pintu Kanal ke Arah Mulut Kanal Intake PLTGU Muara Tawar Pada Tahun 2013 dan 2014 
Dari Gambar 6 dapat dilihat bahwa pada area pintu kanal dari IT-01 sampai dengan IT-165 sepanjang satu kilometer telah terjadi perubahan bahwa penumpukan sedimen atau permukaan yang paling dangkal ditunjukkan dengan gradasi warna merah sedangkan permukaan yang paling dalam ditunjukkan dengan gradasi warna biru di mana pada tahun 2013 yang semulanya penumpukan sedimen atau permukaan yang paling dangkal ditunjukkan dengan gradasi warna merah pada kontur tiga dimensi, yaitu penumpukan pada umumnya terjadi di sepanjang dinding kanal di mana makin mendekati dinding sedimen makin tinggi dan pada tahun 2014 bentuk penumpukan sedimen mulai menyebar ke tengah kanal. Pada tahun 2013 mulai dari IT-165 sampai dengan IT-200 bahwa terjadi pendangkalan dengan pola yang lebih landai yang ditunjukkan pada gradasi warna hijau yang lebih renggang sementara di tahun 2014 terlihat ada cekungan pada tengah kanal yang mengindikasikan bahwa adanya proses pemindahan sedimen. Sedangkan pada area IT-200 sampai dengan mulut kanal bentuk permukaan sedimen pada tahun 2013 yang sebelumnya mulai mendangkal yang ditunjukkan gradasi warna kuning sementara pada tahun 2014 pada umumnya terdapat banyaknya cekungan yang ditunjukkan warna hijau tua yang mengindikasikan adanya proses pemindahan sedimen.

\subsection{Perubahan Luas Sedimen}

Perubahan luas sedimen pada profil melintang yang terjadi antara Bulan Maret 2013 dan Desember 2014 dapat dilihat pada Gambar 7.

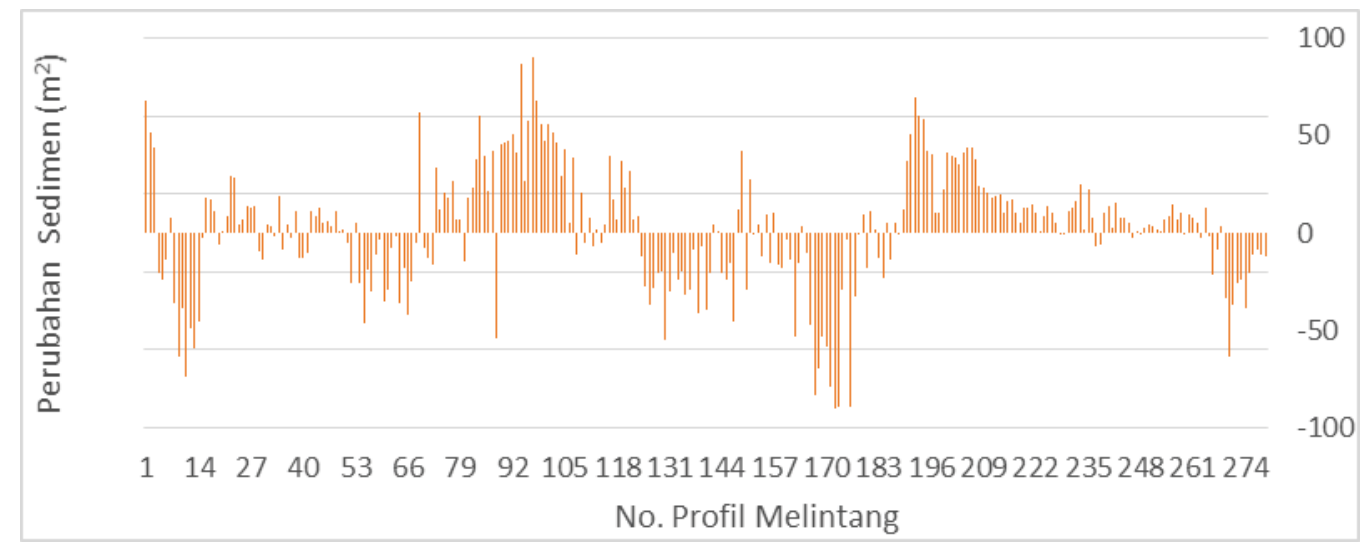

Gambar 7. Perubahan Luas Sedimen Pada Profil Melintang Kanal Intake PLTGU Muara Tawar antara Maret 2013 dan Desember 2014

Nilai perubahan positif mengindikasikan bertambahnya luas sedimen dan sebaliknya nilai perubahan negatif menunjukkan terjadinya pengurangan luas sedimen. Adanya penambahan dan pengurangan yang terjadi menunjukkan adanya proses pemindahan sedimen. Dari Gambar 7 dapat dilihat bahwa penambahan luas sedimen lebih dominan daripada pengurangan. Dengan demikian adanya proses pemindahan dan ada juga proses penumpukan pada luas sedimen adalah sebesar 522,036 meter persegi. Pada umumnya proses penumpukan yang terjadi dan yang terbesar terdapat pada kanal intake yang teratur yaitu dimulai dari profil melintang IT-90 sampai dengan IT-195. Penumpukan yang paling signifikan atau paling besar terdapat pada area Profil Melintang IT-97 yang bertambah, yaitu sebesar 90,40551 meter persegi sedangkan pemindahan sedimen yang paling besar terdapat pada area Profil Melintang IT-172 yang berkurang, yaitu sebesar 89,935381 meter persegi.

\subsection{Syarat Kedalaman Kritis}

Syarat kedalaman kritis yang ditentukan oleh PLTGU Muara Tawar 3 meter di bawah Mean Sea Level (MSL), pada penelitian ini luas kondisi kritis pada Tahun 2013 dan 2014 dapat dilihat pada Gambar 8 dan 9. 


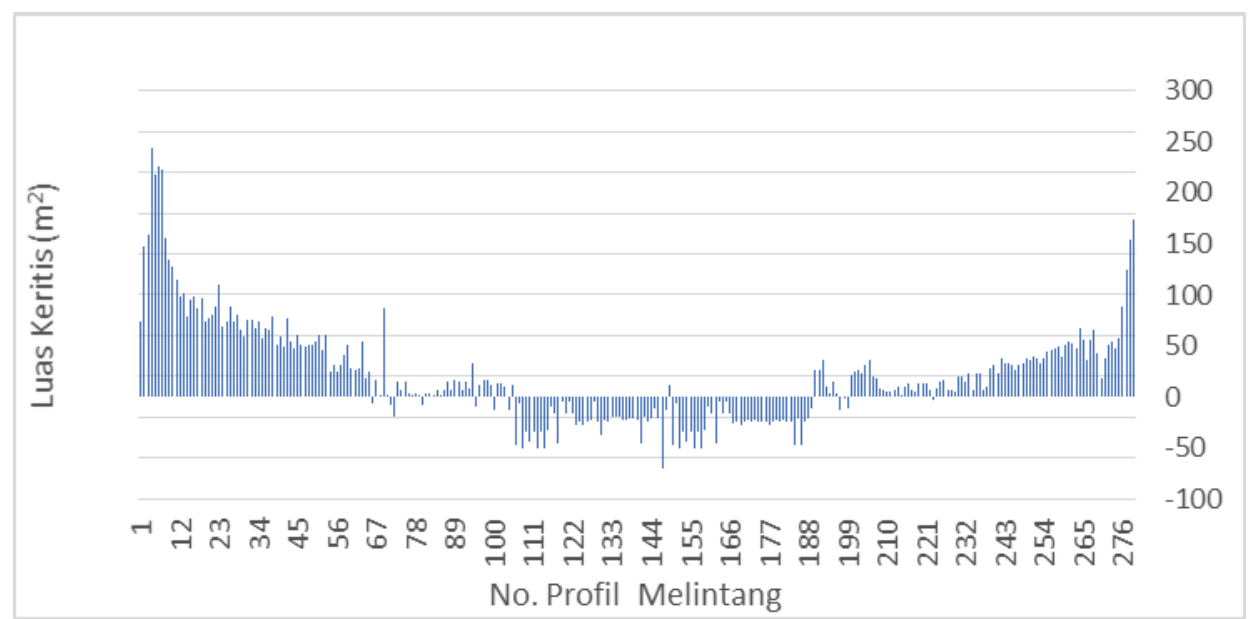

Gambar 8. Luas Kondisi Kritis Pada Profil Melintang Pada Kanal Intake PLTGU Muara Tawar Tahun 2013

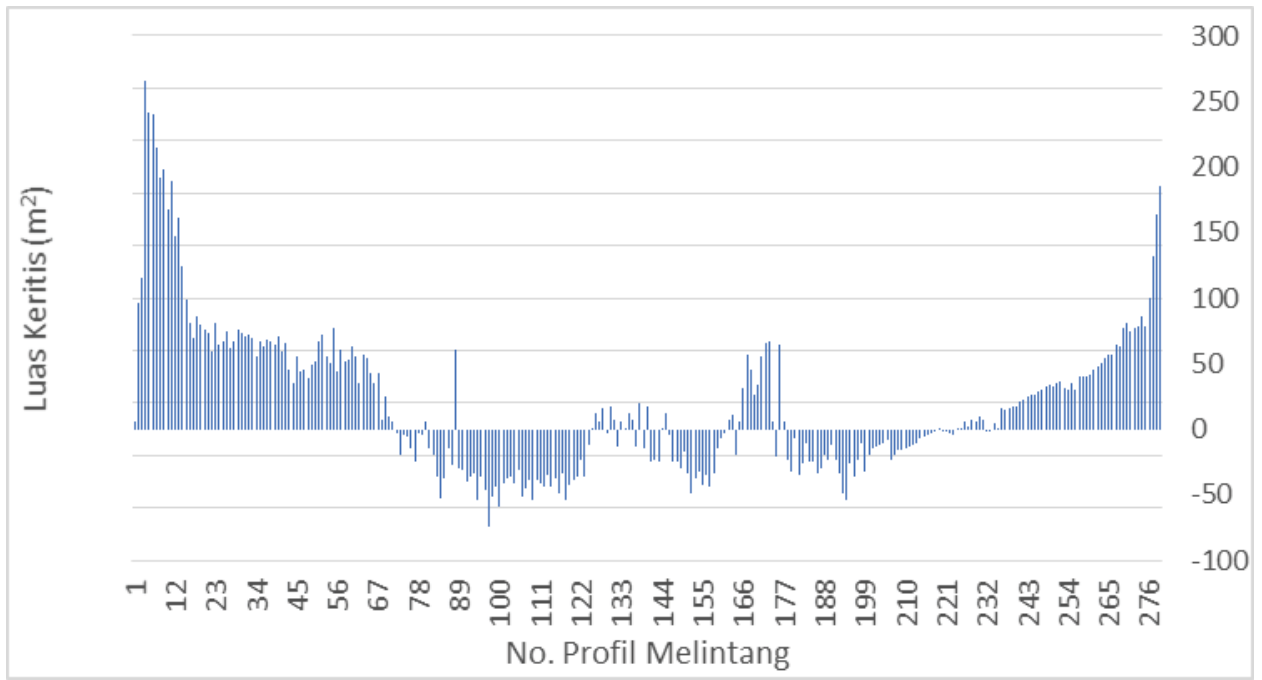

Gambar 9. Luas Kondisi Kritis pada Profil Melintang pada Kanal Intake PLTGU Muara Tawar Tahun 2014

Nilai perubahan negatif mengindikasikan bahwa kondisi kritis pada profil melintang dan sebaliknya nilai perubahan positif menunjukkan tidak terjadinya kondisi kritis pada profil melintang. Yang dimaksud syarat kondisi kritis, yaitu apabila luas sedimen pada profil melintang berada di atas 3 meter. Dari Gambar 8 dapat dilihat bahwa pada tahun 2013 lokasi kondisi kritis yang paling banyak pada umumnya terjadi pada area Profil Melintang IT-106 sampai dengan IT-190. Untuk lokasi kondisi kritis yang paling besar terdapat pada Profil Melintang IT-147 adalah sebesar 70,03644 meter persegi. Sementara pada Gambar 9 dapat dilihat bahwa pada Tahun 2014 lokasi kondisi kritis yang paling banyak pada umumnya terjadi pada area Profil Melintang IT-70 sampai dengan IT-211. Untuk lokasi kondisi kritis yang paling besar terdapat pada Profil melintang IT-97 adalah sebesar 74,40591 meter persegi. Total luas syarat kondisi kritis yaitu sebesar 5.765,512 meter persegi dan jumlah lokasi kondisi kritis pada tahun 2013 adalah sebanyak 94 lokasi profil melintang sedangkan pada Tahun 2014 sebanyak 121 lokasi profil melintang.

\subsection{Analisis Ketersediaan Pasokan Air}

Ketersediaan pasokan air pada penelitian ini ditentukan berdasarkan hasil hitungan volume sedimen dan air yang dapat dilihat pada Tabel 4 . 
Juli Arianto, Ni Made Rai Ratih C. P., Fattahillah P.

Tabel 4. Volume Sedimen dan Air pada Tahun 2013 dan 2014

\begin{tabular}{|c|c|c|c|c|}
\hline Tohun & Volume Sedimen & Perubahan & Volume Air Rata-rata & Perubahan \\
\hline & $\left(\mathrm{m}^{3}\right)$ & $\left(\mathrm{m}^{3}\right)$ & $\left(\mathrm{m}^{3}\right)$ & $\left(\mathrm{m}^{3}\right)$ \\
\hline 2014 & 728689,2444 & \multirow{2}{*}{1219,3664} & 353967,9478 & \multirow{2}{*}{$-314,8099$} \\
\hline 2013 & 727469,878 & & 354282,7577 & \\
\hline
\end{tabular}

Pada penelitian ini volume yang dihasilkan adalah volume sedimen dan volume air serta perubahannya. Perubahan volume sedimen antara tahun 2013 dan 2014 adalah sebesar 1.219,366 meter kubik sedangkan perubahan volume air mengalami pengurangan sebesar 314,809 meter kubik. Data ini menunjukkan bahwa penambahan sedimen menyebabkan berkurangnya pasokan air. Untuk syarat aman pasokan air seharusnya sampai 6 meter di bawah MSL tidak lagi terdapat sedimen. Dilihat dari kondisi yang ada di tahun 2013 berarti pasokan air yang tersedia hanya 32,75\% sementara di tahun 2014 pasokan air yang tersedia hanya $32,69 \%$ dari syarat aman maka untuk memenuhi syarat aman pasokan air maka sedimen sampai 6 meter di bawah MSL yang harus dikeruk baik di tahun 2013 maupun 2014 sebesar lebih dari $60 \%$.

\section{KESIMPULAN}

Pada penelitian ini berdasarkan hasil analisis luas dan volume untuk menjaga ketersediaan pasokan air maka dapat diambil kesimpulan seperti berikut: naik turunnya muka air tidak ekstrem dan drying height tidak terjadi, tapi pendangkalan sedimen kurang dari satu meter mulai terjadi, yaitu sebesar 0,71 meter di bawah MSL pada tahun 2013 dan 0,83 meter di bawah MSL pada tahun 2014; pada tahun 2013 pada umumnya penumpukan sedimen terjadi di sepanjang dinding kanal dan pada tahun 2014 menyebar ke tengah kanal mulai dari pintu kanal sampai dengan mulut kanal; total perubahan luas sedimen antara Maret 2013 dan Desember 2014 adalah sebesar 522,036 meter persegi. Penumpukan yang paling besar terdapat pada profil melintang di 970 meter dari pintu kanal $(90,40551$ meter persegi) dan pemindahan sedimen paling besar pada profil melintang di 1,720 kilometer dari pintu kanal (89,935381 meter persegi); Kondisi kritis pada tahun 2013 adalah sebanyak 94 lokasi profil melintang sedangkan pada tahun 2014 sebanyak 121 lokasi profil melintang; Pada tahun 2013 pasokan air yang tersedia hanya 32,75 \% dari syarat aman dan di tahun 2014 yang tersedia hanya 32,69\% dari syarat aman.

\section{DAFTAR PUSTAKA}

[1] PLTGU Muara Tawar. (2013). "Pengukuran Sedimentasi Di Kanal Intake PLTGU Muara Tawar". Laporan Tahunan PLTGU Muara Tawar, Bekasi Utara.

[2] Achmad, Z. (2011). "Analisis Pengaruh Pola Arus dan Laju Sedimentasi Terhadap Perubahan Batimetri Di Perairan Teluk Tomini Gorontalo". Presentasi Pdf ITS Undergraduate Surabaya. Dipetik pada 5 Maret 2014, Diakses dari http://www.its.ac.id/public/ITS-Undergraduate-17235Presentation-pdf.

[3] Rais, M. (2000). “Analisis Hitungan Volume Endapan Lumpur Studi Kasus Muara Sungai Ciasem, Subang, Jawa Barat”. Skripsi Institut Teknologi Nasional, Bandung.

[4] Pearson, M. (2013). "Reeds Skipper's Handbook for Sail and Power 6th Edition". Adlard Coles Nautical, London.

[5] Heron. (2007). "Teori Lowest Astronomical Tide (LAT)". Dipetik pada 8 Mei 2015, diakses dari www. researchgate. net/.../5562a42908ae6f4dcc953071.pdf 